\title{
Synthesis and characterization of Trichloroisocyanouric acid functionalized mesoporous silica nanocomposite (SBA/TCCA) for the Acylation of Indole
}

\author{
G ROBIN WILSON and AMIT DUBEY* \\ Department of Chemistry, Maulana Azad National Institute of Technology (MANIT), Bhopal, \\ Madhya Pradesh, 462003 India \\ e-mail: dramit.dubey@gmail.com; amitdubey75@yahoo.com
}

MS received 7 January 2016; revised 21 June 2016; accepted 21 June 2016

\begin{abstract}
Trichloroisocyanouric acid (TCCA)-functionalized mesoporous silica nanocomposites (SBA/ TCCA) were synthesized and characterized for the acylation of indole. The uniform incorporation of TCCA inside the SBA-15 matrix was confirmed by standard characterization techniques (PXRD, Adsorption studies, FT-IR, etc.). The catalytic activity studies of SBA/TCCA nanocomposites for acylation of indole showed high selectivity (60-90\%) of the 3-acetyl indole compared to homogeneous TCCA $(50 \%)$. The advantage of solid support for higher selectivity is also explained.
\end{abstract}

Keywords. Trichloroisocyanouric acid; mesoporous silica; acylation; indole.

\section{Introduction}

The rigorous environmental concerns have forced the manufacturing industry across the globe to replace the hazardous homogeneous reagents with recyclable, cost effective and environmental friendly processes. ${ }^{1}$ The development of new heterogeneous systems such as zeolites, clays, heteropoly acids, mesoporous silica and carbon have opened the new avenues for many catalytic applications. ${ }^{2,3}$ Systematic variation in the surface area, pore size and pore volume of these materials generates the flexibility to impregnate many acidic/basic moieties for various applications. ${ }^{4}$ In our continuing research efforts to develop mild acid catalysts, different functionalized mesoporous silica materials were prepared for their effective usages in catalytic and adsorption applications. ${ }^{5-7}$ Trichloroisocyanuric acid (TCCA), one of the highly accepted homogeneous catalyst, acts as a sensitizer to kill bacteria, control algae in water in swimming pools and hot tubs, and has also been used in acidic conversions. ${ }^{8,9}$ However, its corrosive nature to eyes, skin, toxicity and burning effects within a short period of its exposure and the difficulties associated in product recovery limit its practical utilization. ${ }^{9}$ Therefore, heterogenization or functionalization of TCCA into a suitable solid matrix may be beneficial for many important transformations to overcome the above cited difficulties. Recently, thiocyanation of aromatic

*For correspondence compounds, mononitration and dinitration of phenols have been reported over TCCA/ $\mathrm{NH}_{4} \mathrm{SCN} /$ wet $\mathrm{SiO}_{2}$ mixture. ${ }^{10,11}$ However, based on the literature review, TCCA-functionalized SBA-15 via co-condensation method has not been reported for acylation of indole. Therefore, in the present investigation, our interest emerged to synthesize SBA/TCCA nanocomposites for the first time in the liquid phase acylation of indole. Particularly, 3-substituted indoles are industrially important compounds in diverse biological activities such as in platelet activating factor receptor (PAFR) antagonists for septic shock, ${ }^{12}$ anticonvulsant, ${ }^{13}$ for fine chemical industries. ${ }^{13-16}$ Various reagents such as indole salts with acyl chlorides, ${ }^{17,18}$ Vilsmeir-Hack acylations, ${ }^{19}$ Friedel-Crafts acylations, ${ }^{20}$ regioselective synthesis of 3-acyl indoles with anhydrous $\mathrm{SnCl}_{2}$ using nitrobenzene and acetyl chloride as a co-solvent and acylating agent, respectively ${ }^{21}$ have been used for this interesting conversion. Recently, the use of tungstophosphoric acid-modified $\mathrm{H}-\beta$ zeolite was reported for acylation of indole under microwave conditions. ${ }^{22}$ However; all these methods suffer from low yield and lower selectivity of 3-acylated product. Although, the electrophilic attack at 3-position is more facilitated, yet the lower selectivity was usually observed due to the competitive formation of 1-acylated and 1,3-diacylated diindolylmethanes, and self-polymerization of indoles under acidic conditions. ${ }^{23}$ Hence, the 3 -acylated activity and selectivity of 3-acylated indole still remains a challenge in this interesting reaction. 


\section{Experimental}

\subsection{Synthesis of SBA-15/TCCA nanocomposites by co-condensation method}

SBA/TCCA materials were synthesized by nonionic surfactant (poly(ethylene glycol)-poly(propylene glycol)-poly(ethylene glycol), MW = 5800), from Sigma Aldrich), silica source (tetra ethoxy orthosilicate (TEOS), with simultaneous addition of TCCA. Initially, $3 \mathrm{~g}$ of the surfactant was mixed with $80 \mathrm{~g}$ of distilled water followed by hydrolysis with $5.9 \mathrm{~g}$ of conc. $\mathrm{HCl}(35 \%)$ under stirring condition for $1 \mathrm{~h}$ until the solution becomes homogeneous. After the addition of $7.3 \mathrm{~g}$ of TEOS at $35^{\circ} \mathrm{C}$ for $6 \mathrm{~h}$, desired amount of TCCA was added into the reaction mixture was maintained at the molar ratio of $\mathrm{P} 123: \mathrm{H}_{2} \mathrm{O}: \mathrm{HCl}$ : TEOS: TCCA as 1: 8546.9: 306.6: 67.54: 17.65. The solution was kept for $24 \mathrm{~h}$ under stirring condition and the mixture was again subjected to hydrothermal treatment at $100^{\circ} \mathrm{C}$ for $24 \mathrm{~h}$ (without stirring) in a polypropylene bottle. The solid product was filtered and dried at $80^{\circ} \mathrm{C}$. The surfactant was removed by extraction with ethanol/HCl mixture. The synthesized samples were designated as SBA/xTCCA, where x refers the amount of TCCA. To compare the activity of TCCA on other solid supports, equivalent amount of TCCA ( $5 \mathrm{wt} \%$ ) was impregnated on silica gel $\left(\mathrm{SiO}_{2}\right)$ and $\mathrm{Al}_{2} \mathrm{O}_{3}$ using ethanol as solvent. However, efforts were not devoted to characterize $\mathrm{SiO}_{2} /$ TCCA and $\mathrm{Al}_{2} \mathrm{O}_{3} /$ TCCA catalysts as they were chosen as references to compare the activity with almost same amount of acidity.

\subsection{Catalytic studies}

For acylation of indole (Scheme 1), $1 \mathrm{mmol}$ of indole, $1 \mathrm{mmol}$ of acetic anhydride and a suitable solvent were taken in a two-neck round bottom flask. The calculated weight of SBA/TCCA catalyst (10-500 mg) was mixed with the reaction mixture under stirring condition at different temperatures $\left(30-90^{\circ} \mathrm{C}\right)$. The reaction was observed for $24 \mathrm{~h}$ by TLC and the products of the reaction were analyzed by gas chromatography by calculating the response factors of the standard samples using Perkin Elmer gas chromatograph (model Clarus 480) using $10 \%$ OV-17 column.

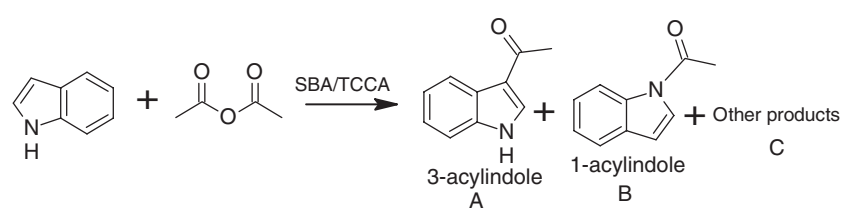

Scheme 1. Acylation of Indole.

\section{Results and Discussion}

\subsection{Physico-chemical Characterization}

Powder X-ray diffraction (PXRD) pattern was recorded on Hecus X-Ray Systems S3 Model using $\mathrm{Cu}-\mathrm{K} \alpha$ radiation $\left(\lambda=1.5404 \AA\right.$ ) from $0^{\circ}-5^{\circ}$. The adsorption studies were performed by using Micromeritics ASAP 2010 analyzer at $-196^{\circ} \mathrm{C}$. BET (Brunauer-Emmett-Teller) method was used to measure surface area whereas $\mathrm{BJH}$ (Barrett-Joyner-Halenda) method was used to calculate the pore size distribution from the desorption isotherm of the sample. The IR spectra $\left(400-4000 \mathrm{~cm}^{-1}\right)$ of the samples were measured with FTIR spectrophotometer (Perkin Elmer) using $\mathrm{KBr}$ pellets. The titration method was used to calculate the number of acidic sites on the catalyst surface. The surface morphology of the catalysts was confirmed by Scanning Electron Microscopy.

The indexing of the diffraction peaks of SBA/xTCCA at (100), (110), and (200) planes (Figure 1) showed two dimensional hexagonal p6mm symmetry identical to SBA-15 materials. ${ }^{24}$ These results pointed out that the materials could retain the ordered mesoporous structure even after the addition of $2 \mathrm{~g}$ of TCCA which is incorporated uniformly inside the mesoporous framework of SBA-15. PXRD pattern of the samples was diminished with increase in the amount of TCCA in SBA/3TCCA nanocomposite (Figure S1 in Supplementary Information (SI)). This is due to the rupture of silica wall thickness at higher concentration of TCCA. Careful analysis of the results indicates that the peak positions are shifted towards lower angle because the simultaneous addition of the hydrophilic ligand TCCA prevents the

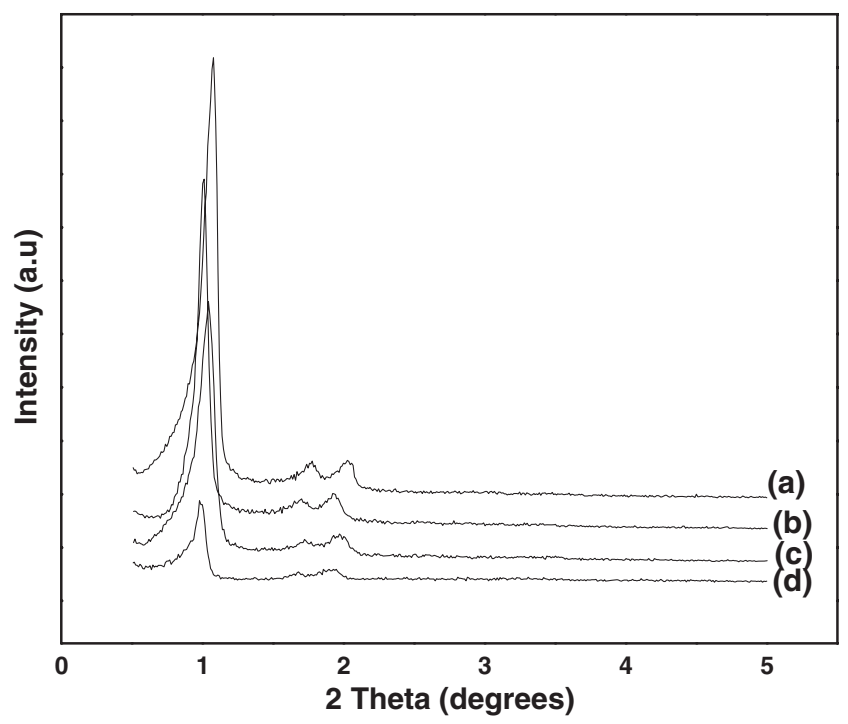

Figure 1. PXRD pattern of (a) SBA-15 (b) SBA/1.5TCCA (c) SBA/2TCCA and (d) SBA/1.5TCCA (after first cycle) nanocomposites. 
hydrophobic interactions between the terminal moiety of the silica source and the long alkyl chain surfactant during the formation of silica-surfactant composite in the miceller solution. Therefore, the terminal organic moiety may not be able to penetrate easily into the micelle which leads to the increase in $d_{(100)}$ spacing. This is in agreement with the previous reports for the co-condensation method. ${ }^{25,26}$

The adsorption studies ( $\mathrm{N}_{2}$ adsorption-desorption) indicated type-IV adsorption isotherm according to IUPAC classification (Figure 2) with an H1 hysteresis loop similar to SBA-15. ${ }^{24}$ These results indicate the presence of large mesopores with narrow pore size distributions (Figure 2 (inset), and Figure S2 in SI).

The shape of the adsorption isotherm of SBA/ 2TCCA is slightly bent due to the greater strain created on the mesoporous silica surface with higher concentration of TCCA. The structural parameters (Table 1) showed that the surface properties were lowered with the increase in the concentration of TCCA in SBA/ xTCCA materials, which further indicate that TCCA has been incorporated inside the mesopores. Furthermore, the mesoporosity of the SBA/3TCCA nanocomposite was completely destroyed (Figure S3 in SI) with significant reduction in the surface area (Table 1). Scanning electron microscopy images (Figure S4 in SI) showed the rod type geometry of SBA/1.5TCCA nanocomposite, similar to SBA-15, which further indicates the uniform distribution of TCCA.

FT-IR spectra of SBA/1.5TCCA and SBA/2TCCA (Figure 3) showed the characteristic peaks similar to homogeneous TCCA. However, presence of some extra peaks for SBA/TCCA nanocomposites may be due to

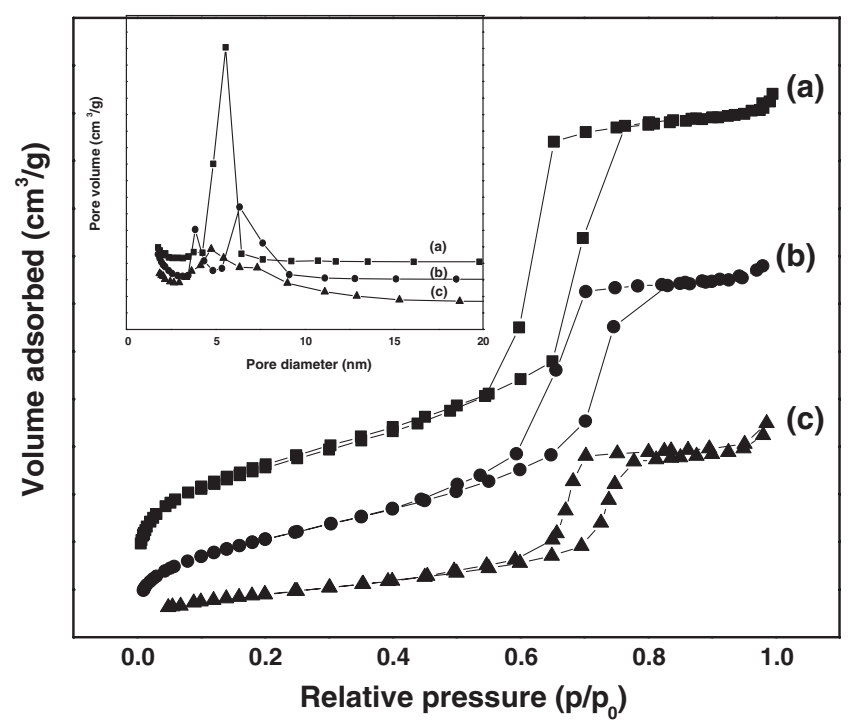

Figure 2. $\mathrm{N}_{2}$ adsorption-desorption isotherms and pore size distribution curves (inset) of (a) SBA-15 and (b) SBA/1.5TCCA and (c) SBA/2TCCA nanocomposites.
Table 1. Structural parameters of the samples.

\begin{tabular}{lccc}
\hline Materials & $\begin{array}{c}\text { Surface area } \\
\left(\mathrm{m}^{2} / \mathrm{g}\right)\end{array}$ & $\begin{array}{c}\text { Pore Volume } \\
\left(\mathrm{cm}^{3} / \mathrm{g}\right)\end{array}$ & $\begin{array}{c}\text { Pore size } \\
(\mathrm{nm})\end{array}$ \\
\hline SBA-15 & 626 & 0.93 & 8.4 \\
SBA/1.5TCCA & 463 & 0.64 & 5.5 \\
SBA/2TCCA & 153 & 0.29 & 4.6 \\
SBA/3TCCA & 68 & 0.13 & 2.8
\end{tabular}

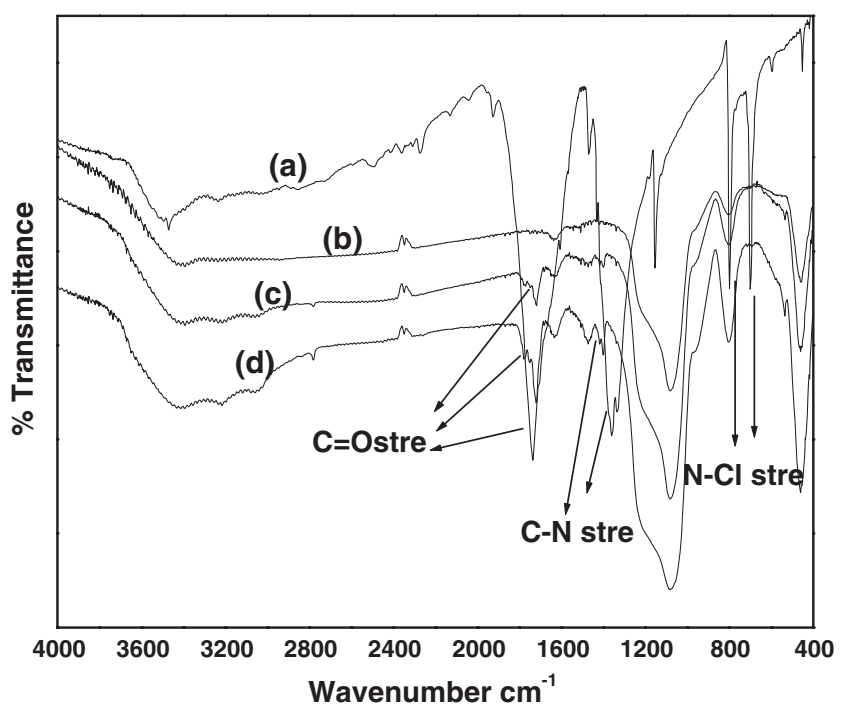

Figure 3. FTIR spectra of (a) Neat TCCA (b) SBA-15 (c) SBA/1.5TCCA and (d) SBA/2TCCA nanocomposites.

the presence of SBA-15 material. A broad peak at $1700-1600 \mathrm{~cm}^{-1}, 1250-1200 \mathrm{~cm}^{-1}$ and $770-800 \mathrm{~cm}^{-1}$ can be attributed to $\mathrm{C}=\mathrm{O}$ stretching, $\mathrm{C}-\mathrm{N}$ stretching and $\mathrm{N}-\mathrm{Cl}$ stretching, respectively, for neat TCCA and SBA/TCCA nanocomposites. These results clearly showed the uniform incorporation of TCCA inside the mesoporous matrix. Acidity of the SBA/1.5TCCA, $\mathrm{SiO}_{2} /$ TCCA and $\mathrm{Al}_{2} \mathrm{O}_{3} /$ TCCA catalysts, calculated by titration method, was observed to be 1.9, 2.1 and $1.7 \mathrm{mmol} / \mathrm{L}$, respectively. ${ }^{7}$

\subsection{Catalytic activity studies}

3.2a Variation of catalysts on the acylation of indole: The catalytic activity studies showed considerably high activity (45-60\%) of the total products with (60-90\%) selectivity of the 3-acylated product in all SBA/TCCA catalysts compared to homogeneous TCCA catalyst under our experimental conditions (Table 2). The results indicated lesser selectivity of the 3-acylated product for SBA/3TCCA catalyst. This may be due to the loss of long range ordering of the mesoporous structure at higher concentration of TCCA. In order to check the effect of solid supports on activity and 
Table 2. Variation of different catalysts on the conversion and the selectivity of the product.

\begin{tabular}{lcccc}
\hline & & \multicolumn{3}{c}{ Selectivity (\%) } \\
\cline { 3 - 5 } Catalyst & a Conversion (\%) & 3-acetyl indole & 1-acetyl indole Other products \\
\hline SBA-15 & 0 & 0 & 0 & 0 \\
TCCA & 75 & 50 & 40 & 10 \\
SBA/1.5TCCA & 45 & 90 & 10 & 0 \\
SBA/1.5TCCA $(2)^{\mathrm{b}}$ & 40 & 90 & 10 & 0 \\
SBA/1.5TCCA $(3)^{\mathrm{b}}$ & 38 & 90 & 10 & 0 \\
SBA/2TCCA & 55 & 85 & 15 & 0 \\
SBA/3TCCA & 60 & 60 & 20 & 20 \\
$\mathrm{SiO}_{2} /$ TCCA & 50 & 70 & 15 & 15 \\
$\mathrm{Al}_{2} \mathrm{O}_{3}$ /TCCA & 45 & 65 & 10 & 25 \\
\hline
\end{tabular}

Reaction conditions: indole ( $1 \mathrm{mmol}), \mathrm{Ac}_{2} \mathrm{O}(1 \mathrm{mmol})$, solvent: hexane, Temp.: $60^{\circ} \mathrm{C}$. ${ }^{\mathrm{a}}$ conversion is based on the product.

${ }^{\mathrm{b}}$ refers to $2^{\text {nd }}$ and $3^{\text {rd }}$ cycle.

selectivity of the 3-acylated product, $\mathrm{SiO}_{2} / \mathrm{TCCA}$ and $\mathrm{Al}_{2} \mathrm{O}_{3}$ /TCCA catalysts were also tested for this reaction under similar reaction conditions. The results showed almost same conversion but with very less selectivity of the 3-acylated product corroborating the necessity of ordered mesoporous support. No conversion was noted using SBA-15 materials inferring that certain acidity is required to achieve the conversion of indole. These observations suggest that the higher selectivity of 3acylated product is due to large surface area, uniform dispersion of acidic centers (SBA/TCCA) and presence of ordered mesoporous support (SBA-15) which was absent in homogeneous medium and other supports. Hence, SBA/1.5TCCA is selected for further studies.

3.2b Effect of the solvent(s): Screening of different solvents showed nearly the same conversion over all the polar solvents with less selectivity of the 3-acylated products (Table 3 ). The formation of some polymerized

Table 3. Influence of different solvents on conversion and selectivity of the product over SBA/1.5TCCA catalyst.

\begin{tabular}{lcccc}
\hline & & \multicolumn{3}{c}{ Product selectivity (\%) } \\
\cline { 3 - 5 } Solvent & $\begin{array}{c}\text { Conversion } \\
(\%)\end{array}$ & $\begin{array}{c}\text { 3-Acetyl } \\
\text { Indole }\end{array}$ & $\begin{array}{c}\text { 1-Acetyl } \\
\text { Indole }\end{array}$ & $\begin{array}{c}\text { Other } \\
\text { products }\end{array}$ \\
\hline $\mathrm{CH}_{2} \mathrm{Cl}_{2}$ & 50 & 60 & 25 & 15 \\
$\mathrm{CHCl}_{3}$ & 55 & 65 & 20 & 15 \\
$\mathrm{CCl}_{4}$ & 50 & 60 & 40 & 0 \\
$\mathrm{CH}_{3} \mathrm{OH}$ & 70 & 65 & 15 & 20 \\
$\mathrm{C}_{2} \mathrm{H}_{5} \mathrm{OH}$ & 75 & 60 & 15 & 25 \\
$\mathrm{CH}_{3} \mathrm{CN}$ & 65 & 55 & 30 & 15 \\
$\mathrm{CH}_{3} \mathrm{COCH}$ & 60 & 50 & 35 & 15 \\
$\mathrm{C}_{6} \mathrm{H}_{14}$ & 45 & 90 & 10 & 0 \\
\hline
\end{tabular}

Reaction conditions: indole $(1 \mathrm{mmol}), \mathrm{Ac}_{2} \mathrm{O}(1 \mathrm{mmol})$, SBA/1.5TCCA (100 mg), Temp.: $60^{\circ} \mathrm{C}$. products was also observed in polar solvents under similar reaction conditions. In contrast, slightly lower conversion but very high selectivity $(90 \%)$ of 3 -acylated product was observed using hexane as solvent without formation of any side products or polymerized products. These observations may be attributed to the nonpolar nature of hexane which maintains the optimum acidity in the reaction medium to stabilize the transition state more to achieve the formation of 3-acylated product. The high selectivity of 3-acylated product and the lesser requirement of the catalyst are industrially beneficial under environmentally friendly conditions.

3.2c Effect of indole: acetic anhydride ratio: The results of catalytic activity (Figure 4) showed that an increasing trend of the conversion with increase in the ratio of indole: acetic anhydride. However, the selectivity of the 3-acylated indole was lowered at higher concentration of acetic anhydride due to the formation of more side products. This may be due to excess acylating agent which enhances the rate of the reaction and the unused acetic anhydride facilitates the formation of over-acylated products (diacylated products and polymerized products). Therefore, indole: acetic anhydride ratio (1:1) was selected for further studies.

$3.2 \mathrm{~d}$ Variation of the catalyst weight: Results of variation of the catalyst weight (Figure 5) showed that the total conversion increased initially up to $250 \mathrm{mg}$ of the catalyst with (85-90\%) selectivity of the 3-acylated product. The conversion of the 3 -acylated product was reduced with further increase in the catalyst weight up to $500 \mathrm{mg}$. This lowering of activity is because of the blockage of the active sites and possible repulsion between the adsorbed species on mesoporous silica 


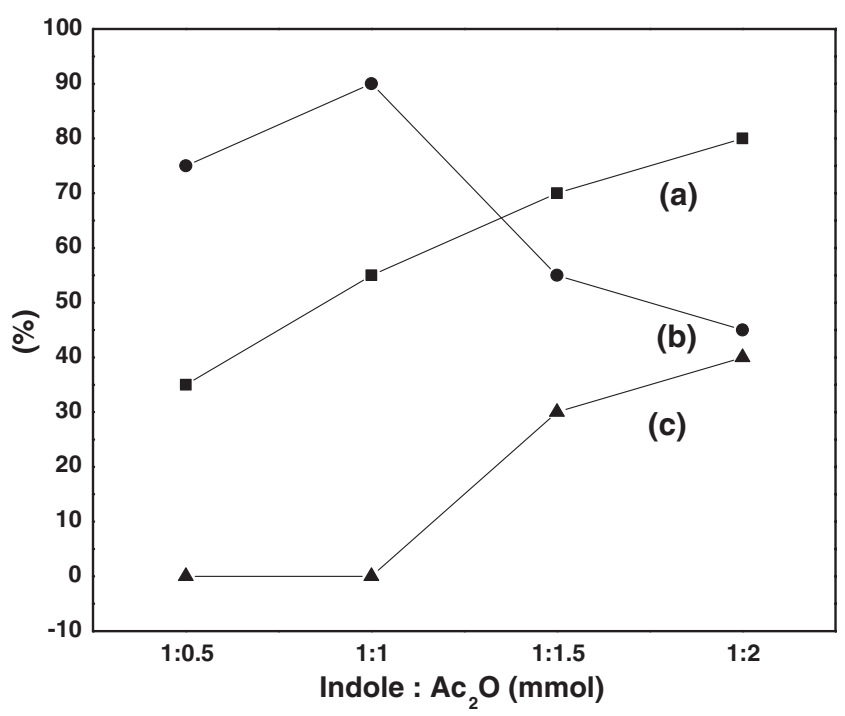

Figure 4. Effect of indole to acetic anhydride ratio on (a) conversion, (b) selectivity of 3-acetyl indole and (c) selectivity of other products over SBA/1.5TCCA catalyst. (Reaction conditions: SBA/1.5TCCA (100 mg), Solvent: hexane, Temp.: $\left.60^{\circ} \mathrm{C}\right)$.

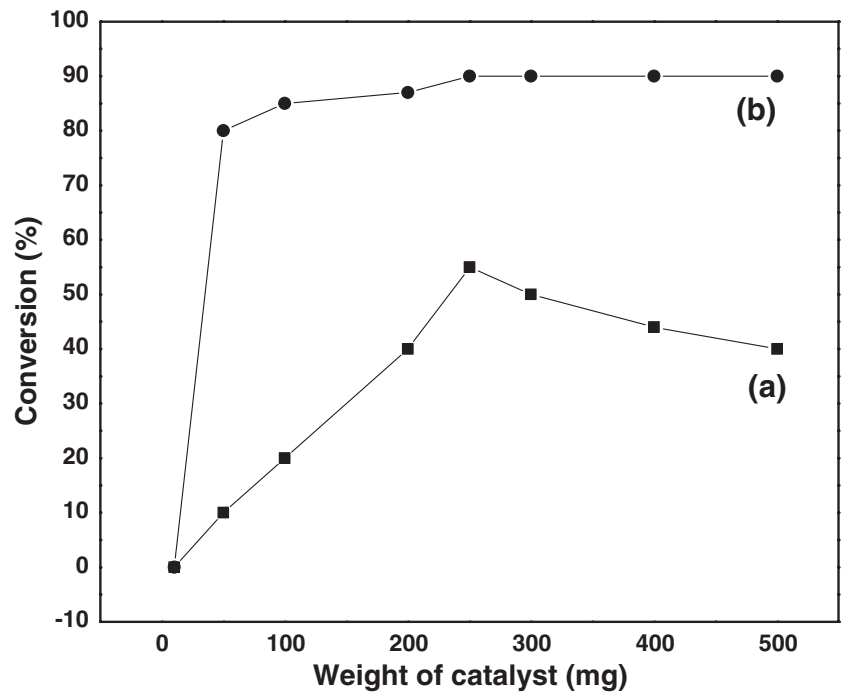

Figure 5. Variation of weight of catalyst on (a) conversion and (b) product selectivity (for 3-acetyl indole) over SBA/1.5TCCA catalyst. (Reaction conditions: indole (1 mmol), $\mathrm{Ac}_{2} \mathrm{O}(1 \mathrm{mmol})$, solvent: hexane, Temp.: $\left.60^{\circ} \mathrm{C}\right)$.

surface. However, selectivity of 3-acylated product remained constant irrespective of the catalyst weight. Therefore, the catalyst weight of $100 \mathrm{mg}$ and hexane as solvent was selected for further studies.

3.2e Effect of the reaction temperature and time: The effect of the reaction time (Figure 6) was carried out at different temperatures $\left(30-90^{\circ} \mathrm{C}\right)$ for $24 \mathrm{~h}$. The conversion of the products increased up to $60^{\circ} \mathrm{C}$ and then showed decreasing trend up to $\left(90^{\circ} \mathrm{C}\right)$. This

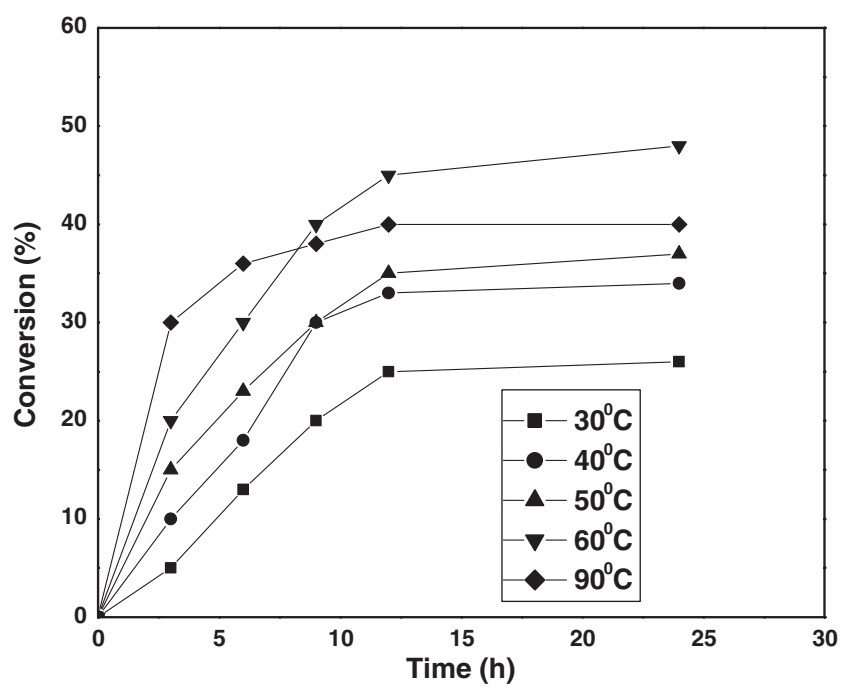

Figure 6. Variation of the reaction temperature and time on the conversion of the product over SBA/1.5TCCA catalyst. (Reaction conditions: indole $(1 \mathrm{mmol}), \mathrm{Ac}_{2} \mathrm{O}(1 \mathrm{mmol})$, SBA/1.5TCCA (100 mg), solvent: hexane, Temp.: $\left.60^{\circ} \mathrm{C}\right)$.

lowering in conversion at higher temperatures can be due to the polymerization of the reactant (indole). Hence, the optimum reaction temperature of $60^{\circ} \mathrm{C}$ was chosen for the reaction. Time on stream studies indicated that total conversion of the products increased with the increase in the reaction time and the maximum conversion could be achieved within $12 \mathrm{~h}$ but the reaction was monitored for $24 \mathrm{~h}$ to see the possibility of the formation of any over-acylated or inter-converted products. No change in the conversion and selectivity was noted inferring the stability of SBA/TCCA with time.

\subsection{Reusability of catalysts}

The reusability and heterogeneity of the catalyst were tested with $250 \mathrm{mg}$ of the catalyst with the PXRD analysis after the first cycle. The catalyst was filtered and washed with methanol, water and finally with acetone. The dried catalyst $\left(120^{\circ} \mathrm{C}\right)$ was tested again for the second cycle. A small reduction in the conversion (5-7\%, Table 2 and Figure S5 in SI) but with no change in the selectivity of 3-acetyl indole was noted up to third cycle. The mesoporous nature of the used catalyst was confirmed by PXRD (Figure 1).

\section{Conclusions}

SBA/TCCA nanocomposites were synthesized by cocondensation method and characterized for the acylation of indole. Very high selectivity of 3-acetyl indole (60-90\%) was observed over SBA/TCCA catalysts using hexane as solvent at $60^{\circ} \mathrm{C}$. Different reaction 
parameters were optimized for this interesting transformation. Further efforts are in progress for acylation/ alkylation of other significant aromatic transformations.

\section{Supplementary Information (SI)}

Supplementary information includes the PXRD pattern of SBA/3TCCA (Figure S1), pore size distribution curve of (a) SBA-15 and (b) SBA/1.5TCCA \& (c) SBA/ 2TCCA nanocomposites (Figure S2), $\mathrm{N}_{2}$ adsorptiondesorption isotherms (Figure S3) of SBA/3TCCA nanocomposites, SEM images (Figure S4) of (a) SBA-15 \& (b) SBA/1.5TCCA nanocomposites and reusability data (Figure S5) of SBA/1.5TCCA catalyst. Supplementary information is available at www.ias.ac. in/chemsci.

\section{Acknowledgment}

AD thanks MANIT-Bhopal for help and support.

\section{References}

1. Wight A P and Davis M E 2002 Chem. Rev. 1023589

2. Hoelderich W F 2000 Catal. Today 62115

3. Sheldon R A 1997 Chem. Ind. 1212

4. Corma A 1997 Chem. Rev. 972373

5. Sachdev D and Dubey A 2013 Catal. Commun. 3939

6. Sachdev D, Wilson G R, Srivastava N M and Dubey A 2014 Catal. Commun. 5190

7. Sachdev D, Dubey A, Wilson G R and Sharma A 2015 New J. Chem. 392633
8. Fujioka H, Murai K, Kubo O, Ohba Y and Kita Y 2007 Tetrahedron 63638

9. Ye Y, Wang Y, Liu R, Zhang G, Zhang Q, Chen J and Liang X 2003 Chem. Commun. 212714

10. Zolfigol M A, Ghaemi E and Madrakian E 2003 Synlett 44191

11. Akhlaghinia B, Pourali A R and Rahman M 2012 Synth. Commun. 421184

12. Albert D H, Luo G, Magoc T J, Tapang P, Holms J H, Davidsen S K, Summers J B and Carter G W 1996 Shock 6112

13. Keasling H, Willette R and Szmuszkovicz J 1964 J. Med. Chem. 794

14. Garratt P J, Vonhoff S, Rowe S J and Sugden D 1994 Med. Chem. Lett. 41559

15. Kumar D, Kumar N M, Chang K H and Shah K 2010 Eur. J. Med. Chem. $\mathbf{4 5} 4664$

16. Kumar D, Kumar N M, Akamatsu K, Kusaka E, Harada $\mathrm{H}$ and Ito T 2010 Bioorg. Med. Chem. 203916

17. Bergman J and Venemalm L 1990 Tetrahedron 466061

18. Yang C X, Patel H H, Ku Y Y, Shah R and Sawick D 1997 Synth. Commun. 272125

19. Ketcha D M and Gribbe G W 1985 J. Org. Chem. 505451

20. Eyley S C, Giles R G and Heany H 1985 Tetrahedron Lett. 264649

21. Ottoni O, Neder A V F, Dias A K B, Cruz R P A and Aquino L B 2001 Org. Lett. 31005

22. Bai G, Li T, Yang Y, Zhang H, Lan X, Li F, Han J, Ma Z, Chen Q and Chen G 2012 Catal. Commun. 29114

23. Kamal A and Qureshi A A 1963 Tetrahedron 19513

24. Kruk M, Jaroniec M, Ko C H and Ryoo R 2000 Chem. Mater. 121961

25. Yokoi T, Yoshitake H and Tatsumi T 2004 J. Mater. Chem. 14951

26. Rosenholm J M and Lindén M 2007 Chem. Mater. 195023 